\title{
The Busy General Practitioner's Reference Guide to Increasing Physical Activity Levels in the British Population and Associated Benefits/Risks: A Review of the Literature
}

Phil Cox*

Centre for Sport and Exercise Medicine, Queens Medical Centre, Nottingham, UK

\begin{abstract}
Whilst most General Practitioners (GPs) recognise the importance that physical activity plays in a healthy nation, many feel unprepared to provide physical activity counseling. GPs therefore do not routinely include physical activity in the consultation as readily as alcohol or tobacco, despite inactivity having a similar health burden. This review of relevant literature using Embase, SPORTDiscus, PubMed, and the Cochrane Library intends to refresh GP's knowledge regarding the vast benefits of physical activity and to investigate the evidence concerning the risks physical inactivity. In addition, an evaluation of the efficacy of interventions to increase PA levels will be undertaken.
\end{abstract}

Keywords: Exercise; Exercise therapy; Economics; Family practice; Health promotion/economics; Health promotion/methods; Humans; Life style; Motor activity; Physical fitness; Rescriptions/economics

\section{Introduction}

\section{An inactive nation}

The disease burden associated with a reduction in Physical Activity (PA) amongst the population has become increasingly apparent, in 2009 inactivity was the "fourth leading risk factor for non-communicable diseases" (World Health Organisation (WHO), 2010) and accounted for 5.3 million out of 57 million worldwide deaths in 2008 [1]. In the United Kingdom (UK), physical inactivity (patients who do not meet Government guidelines) is responsible for $3.1 \%$ of morbidity and mortality at a cost of over $£ 1.8$ billion to the National Health Service (NHS) [2]. When indirect costs (days off work etc.) are included this figure rises to $£ 8.3$ billion [2]. These costs are particularly significant as the Government has asked the NHS to make annual savings of $£ 20$ billion to cope with rising expenditure from an ageing population [3]. Aside from financial costs, it is estimated that 35,000 lives could be saved [2] if the inactive UK population, $61 \%$ of men and $71 \%$ of women in 2008, met Government guidelines for PA [4].

Healthcare has been identified as one of the eight sectors which can influence physical activity levels (PALs) (National Physical Activity Plan, 2010) and General Practitioners (GPs) are in a unique position when creating projects and schemes that will improve PALs in the population. The specialty contains doctors who are aware of the scale of the problem, the benefits of rectifying the problem, have regular contact with patients and have the skill-set to introduce appropriate and effective public health measures within multidisciplinary teams.

\section{Why is this review needed?}

Although public health campaigns focus on the benefits of physical activity, there are risks associated with increasing PA and these are often overlooked or absent from PA campaigns [5,6].

Many clinicians currently feel unprepared to provide PA counselling [7], resulting in a five-fold reduction in PA promotion amongst those unprepared practitioners [8]. It will also highlight the substantial benefits to increasing PA levels to healthcare professionals. The majority of GPs and nurses recognise that increased PA is important for health $[8,9]$ but many do not see PA promotion to be a priority in practice or relevant to the consultation [7]. Healthcare professionals are often more concerned about tackling tobacco and alcohol consumption [10] despite inactivity having a similar health burden [11]. This review of the literature aims to refresh clinician's knowledge regarding the vast benefits of physical activity and to investigate the evidence concerning the risks physical inactivity. In addition, an evaluation of the efficacy of interventions to increase PA levels will be undertaken. This will allow GPs to have the necessary knowledge and tools to enable them to play a role in the promotion of PA.

\section{Review process}

This literature review included resources from electronic documents, peer-reviewed journals, organisation/Government websites and textbooks. To compile a database of relevant literature from 1955-current day and written in English, searches were undertaken using Medline, Embase, SPORTDiscus, PubMed, and the Cochrane Library. These searches included various combinations of keywords and as the number of articles returned was deemed excessive $(>3000)$ various exclusions were added until a manageable number of articles was returned. The titles of these articles were examined and the 642 deemed 'potentially relevant' were added to the database. In order to feasibly investigate the literature, the numbers had to be reduced further and so the abstracts were evaluated with those articles not relevant to the project being discarded, leaving 218 articles to be fully reviewed. Government documents on PA were also searched for using Google, yielding 57 articles and a further 53 journals/articles were added to the database by reviewing the reference lists of existing articles.

\section{Benefits of physical activity}

Public campaigns to promote PA often focus on the health benefits

*Corresponding author: Phil Cox, Centre for Sport and Exercise Medicine, Queens Medical Centre, Derby Road, Nottingham, UK, Tel: 07754184839; E-mail: Phil.cox86@gmail.com

Received April 16, 2013; Accepted April 24, 2013; Published April 28, 2013

Citation: Cox P (2013) The Busy General Practitioner's Reference Guide to Increasing Physical Activity Levels in the British Population and Associated Benefits/Risks: A Review of the Literature. J Gen Pract 1: 101. doi: 10.4172/23299126.1000101

Copyright: (C) 2013 Cox P. This is an open-access article distributed under the terms of the Creative Commons Attribution License, which permits unrestricted use, distribution, and reproduction in any medium, provided the original author and source are credited. 
of increasing PA in several key public health areas identified by review articles [1,12-14]. These include cardiovascular disease, hypertension, obesity, type 2 diabetes, breast cancer, colon cancer, rheumatoid arthritis, pregnancy, chronic obstructive pulmonary disease, osteoarthritis, osteoporosis and depression. In addition to these benefits, being physically active (meeting or exceeding Government guidelines for PA) has been shown by the Physical Activity Guidelines Advisory Committee (PAGAC) (2008) to reduce mortality from all causes by $20-30 \%$. Large, prospective studies such as Leitzmann and Park [15] which included over 1.2 million person-years of follow up have demonstrated a causal link between inactivity and mortality by comparing inactive individuals to those whose PA improves across multiple assessments and noting the mortality reductions associated with physically active individuals. These benefits are seen in all demographics, including the obese and smokers, although the mortality reduction is lessened in these groups. Even those undertaking less PA than Government guidelines will still benefit from a reduction in the relative risk of mortality $(0.81)$. Observational studies have also demonstrated that there is a dose-response relationship, with an increase in intensity or quantity leading to a reduction in mortality rates, between PA levels and all-cause mortality [16]. It must be noted that as these are observational studies, further evidence is required to confirm these dose-relationship findings.

\section{Efficacy of interventions to increase physical activity}

Currently only four methods of increasing PA levels are recommended by the National Institute for Clinical Excellence (NICE) (2006);

- Brief interventions in primary care

- Exercise referral schemes (ERS)

- Pedometers

- Community-based exercise programmes for walking and cycling

In addition to these methods, the use of exercise 'Green Prescriptions' has been increasingly commonplace.

\section{Brief Interventions in Primary Care}

With $78 \%$ of adults in the UK visiting their General Practitioner (GP) at least once between 2009-2010 (Information Services Division, 2011), interventions based in Primary Care have been shown in Cochrane reviews to make a significant impact in key public health matters such as tobacco [17] and alcohol consumption [18]. Patients are more receptive to healthcare advice when it is delivered by a GP [19] as they are seen as "credible sources of healthcare information" [20]. GP's typically see patients in an environment where patients are receptive to engaging in discussion about health promotion [21] and a discussion about PA promotion could easily be introduced.

Interventions can take several forms, including referral to ERS's, but typically involve advice and the delivery of written information. Orrow et al. [22] undertook a meta-analysis and found that "the number needed to treat with a physical activity promotion intervention for one additional sedentary adult to report recommended levels of activity at 12 months was 12 " in patients self-reporting PA. Estimates of the number needed to treat for Primary Care interventions related to smoking vary from 50-120 [17]. These interventions are more cost effective than many pharmaceutical interventions that are routinely provided by Primary Care Practices, with the cost per quality-adjusted life year (QALY) of turning a 'sedentary' patient into an 'active' one between $£ 267$ to $£ 2,960$ [23]. This is well within the NICE guidance that an intervention should have a cost of up to $£ 20,000$ to $£ 30,000$ per QALY (NICE 2008).

\section{Exercise Referral Schemes}

ERS's, also known as exercise prescriptions, have been shown to have improvements in patients' PA levels on completion [23-25]. They typically offer "personalized secondary prevention located in primary healthcare involving the General Practitioner or other primary healthcare staff" [25]. A recent evaluation of the cost effectiveness of the Welsh Government's National Exercise Referral Scheme (NERS) demonstrating increased PA levels in all participant groups (odds ratio=1.19) except those referred with mental health disorders as their primary diagnosis [26]. Uptake of the scheme proved to be successful at $85 \%$, however the NERS suffers from a weakness of many ERS's in that a large proportion of the participants failed to complete the scheme, $14.9 \%$ failed to attend and $41.3 \%$ did not complete the programme. Despite the high drop-out rate, due to the low cost of the NERS ( $£ 385$ per participant), the cost per QALY was calculated to be was $£ 12,111$ or $£ 9,741$ if participants contribute $£ 2$ per session, well within NICE guidelines (2008). Anokye and Trueman [27] demonstrated that the cost per QALY reduces further when schemes are targeted at sedentary patients suffering from obesity, hypertension or depression due to cost savings associated with the treatment of the chronic disease in addition to those gained from a reducing inactivity. These findings are broadly similar to those in other countries, and the most recent review by Pavey et al. [28] found adherence rates of $49 \%$ for observational studies and $43 \%$ for randomised controlled trials. Although studies lack sufficient power to calculate statistics, baseline activity, obesity and age seem to be the only factors influencing whether patients complete the ERS.

Although schemes such as the NERS involve supervision of participants, a 10 week study found that supervised sessions have little benefit over non-supervised prescriptions [29]. This could be significant if these findings are replicated in long-term studies as it would provide a substantial cost saving.

Whether these improvements have any clinical significance is still the subject of much debate. NICE guidance (2006) stated that ERS's should "not be commissioned in primary care outside of well designed research studies" and this is not due to be updated until March 2013 (NICE, personal communication [30]; July 2012). NICE guidance on ERS's has not been disputed by recent meta-analyses which demonstrated that the proportion of patients involved in ERS's who met Government guidelines for PA only increased by $11 \%$ [28] and $16 \%[14]$.

\section{Pedometers}

Pedometers have been displayed in numerous studies to improve PA levels and are relatively inexpensive in addition to providing instantaneous output measures that are easily analysed by those with low literacy rates [31]. Average improvements over varying time periods up to and including 20 weeks has been calculated at 2,000 steps per day compared to control $[32,33]$.

It must be noted however that most pedometer studies focus on 10,000 steps as their output measure, as this was the goal that pedometers were initially designed to achieve [34]. Le Masurier et al. [11] demonstrated that "individuals who accumulate 10,000 steps/ day are more likely to meet the PA guidelines" but improvements in PA guidelines and step-counts cannot be directly compared as the correlation is insufficient [35]. Additionally, most studies focus on 
short-medium term improvements and the impact of pedometers on long term (>12 months) changes in PA is unknown.

\section{Community-based exercise programmes for walking and cycling}

'Active travel', where people commute using methods involving $\mathrm{PA}$, has gained considerable interest in recent years as the health benefits of reducing congestion (and hence air pollution) and being active gain public attention. A 2006 NICE review of "the effectiveness of community-based walking and cycling programmes to promote physical activity in adults" showed that whilst popular amongst patients, there is little evidence to support their promotion. Various studies produced conflicting results and were of insufficient quality to quantify the effect (if any) of these interventions on the number of patients meeting PA. Jarrett et al. [34] has however demonstrated that over the next 20-years, up to $1 \%$ of the annual NHS budget for England and Wales could be saved by increasing walking and cycling in urban areas [36].

\section{Exercise Prescriptions}

Exercise prescriptions, often referred to as 'Green Prescriptions', commonly used in clinical practice is based on recommendations from the US Surgeon General's 1996 report and was first developed by the Hillary Commission (New Zealand) in 1997. They differ from ERSs in that exercise prescriptions do not provide activities for patients to attend, merely supplying advice as to what patients should be undertaking. Exercise prescriptions most recently been updated by the American College of sports medicine to include prescriptions for various health conditions such as hypertension, cardiovascular disease, obesity, type 2 diabetes, osteoarthritis, osteoporosis and depression [30] and are shown in Appendix 2. Typically exercise prescriptions do not involve supervision and a 10 week study found that supervised sessions have little benefit over non-supervised prescriptions [28].

Elley et al. [19] demonstrated that $15 \%$ of inactive patients receiving an exercise prescription met government guidelines after 12 months compared to $5 \%$ in the control group. The Writing Group for the Activity Counseling Trial Research Group [37,38] did not find any statistically significant increases in cardiovascular fitness amongst male participants but showed a mean difference in VO2max of 73.9 $\mathrm{mL} / \mathrm{min}$ between participants given exercise prescription and controls. A cohort study by Sorensen et al. [24,25] in Denmark found that one in three participants achieved an increased PAL (of greater than $1 \mathrm{MET}), 4$ months after being given an exercise prescription, similar improvements were seen at 10 and 16 months although a gain of 1 MET is of clinical significance is subject to debate. It must be noted however that the base line average METs (40) was relatively high compared to normal populations.

One theory as to why exercise prescriptions have a relatively low efficacy was proposed by Prochaska and Marcus [36], entitled 'the stage of change theory'. This theory postulates several stages into which people can be categorised when starting or maintaining new health behaviours [39]. These stages are:

1. Pre-contemplation

2. Contemplation

3. Preparation

4. Action

\section{Maintenance}

The stage of the model that participants are at when they are given an exercise prescription may have an effect on their change in PALs from the scheme. It is suggested that a patient in the pre-contemplation stage who is being introduced to the idea of increasing PA for the first time may have poorer adherence to an exercise prescription than someone in the preparation stage. Some research has been conducted into the effect that a participant's stage has on the changes in PALs from an exercise prescription but studies have found different contradicting results. Calfas et al. [37] and Marcus et al. [38] reported positive results from trials analysing the effects of PA in participants in various stages of the model but this contradicts the later work of Naylor et al. [39] and Blissmer and McAuley [40] which showed no association between stage of the model and change in PALs when compared to controls [40-43]. It is important to note however that these studies only looked at the short term effects with these studies ranging in duration from 6 weeks to 6 months. A trial looking at a longer duration found short term associations which were not apparent in the long term $(>12$ months) [44], although this study focused on overweight individuals and so results must be interpreted with care.

\section{Risks Associated with Increasing Physical Activity Levels}

\section{Sudden cardiac death}

With recent high-profile cases such as Fabrice Muamba gaining much media attention, sudden cardiac death (SCD), defined as "death occurring within one hour of the onset of symptoms in a person with previously known or unknown heart disease" [45], is one of the most serious and high profile risks of engaging in PA. It is often a concern to people considering commencing an exercise programme [46]. SCD has a low incidence, 1 in 43,770 participants per year when considering athletes less than 30 years of age [47]. Corrado et al. [43] found that the relative risk of SCD was 2-4 in young athletes compared to inactive controls. SCD predominantly occurs during periods of medium-low oxygen demand such as during the warm up and inactive periods of matches [31]. Despite the severity of SCD, there is still great debate about the complex aetiological pathways involved $[48,49]$ and the definition of SCD varies between studies [50].

The mechanisms of death vary with age, young athletes ( $<35$ years) predominantly have congenital or cardiovascular causes (hypertrophic cardiomyopathy accounts for $46 \%$ of deaths). The origin of SCD in older athletes (>35) however is caused by myocardial infarctions secondary to underlying coronary artery disease in the majority of cases [49].

Studies from the 1980's have shown that whilst unfit individuals undertaking PA increase their risk of SCD by 5,600\% during the exercise, individuals routinely engaging in PA have substantially lower lifetime relative risk (0.6) of SCD compared to inactive controls [51]. Exercise is therefore both a protective factor (long-term) and a causal factor (short-term) in SCD.

\section{Injury}

Risk of injury has been cited as a major barrier to entry for increasing PA levels in the population [52] and injury is a known risk factor for the development of osteoarthritis $[53,54]$, although more studies are needed to calculate the relative risk [53]. Reliable information on injuries from PA and sport are scarce; however statistics produced for the European Commission found that 4.5 million European Union citizens over 15 years old were treated for sports injuries (as defined by the European 
Injury Database) in Accident and Emergency Departments annually between 2005-2007 [55]. The majority of injuries in any population are believed to be preventable with good athlete education, appropriate kit and application of rules/laws [56,57]. Studies investigating the effects of introducing compulsory head protection in cricket have shown a $50 \%$ reduction in head, neck and facial injuries [58] and law changes in karate have dramatically reduced injuries [59]. Care must however be taken to ensure that increased protection for the athletes does not encourage an increase is risk-taking behaviour, which is believed by many to be one of the most significant factor in injury risk [60]. Prevention of sports injuries is still poorly researched however, as highlighted by a number of articles $[57,61]$. There are currently no studies investigating correlations between injury and inactivity.

There is also insufficient data investigating the prevalence/relative risk of injury with increasing PA rather than in organised sport. Stress fractures are one area that may be subject to an increased relative risk with increased PA, as they typically develop when bone is "exposed to repetitive, cyclical, high volume, or intense exercise, mainly when an individual significantly increases activity levels over a short period of time" [62]. Current opinion however is that increasing PA levels by engaging in more low-impact PA (walking, gardening, cleaning etc.) rather than organised/formal 'sport' would be unlikely to increase the relative risk of injury much beyond that for standard activities of daily living [55].

Although several studies have investigated return to work (RTW) following injury, there is currently no research on the effects of injury on physical activity levels. This lack of information is thought to be the major reason why there is so little policy relating to injury published by Governments [63]. Future research is needed to investigate if factors affecting RTW are the same as those affecting PA levels. Key predictors of RTW are suspected to be applicable to changes in postinjury PA levels, with a prospective cohort study by Clay et al. (2010) demonstrating that strong recovery beliefs amongst participants increase the odds of returning to work at 12 weeks and 6 months by 16.7 and 3.9 times respectively. Gender [64-66] and depression status [67] do not have any effect on RTW times in various injury studies looking at injuries sustained both from trauma and non-traumatic causes. More data are expected to be available on these findings when the UK wide "Impact of injuries study" results are published later this year [68]. Studies investigating the factors impacting return to sport, although limited, suggest that fear of re-injury is a major barrier in addition to other psychological issues [69]. It would be of interest if these effects were further investigated in relation to changes in PA levels with injury.

\section{Female Athlete Triad}

Reliable prevalence data are limited for Female Athlete triad (FAT), which consists of "osteoporosis, disordered eating and menstrual disorders" [70], amongst athletes and the general population. Although data are limited, the American College of Sports Medicine has reported that the prevalence is much higher in female 'lean-build' athletes (such as runners) compared to controls, $31 \%$ and $5.5 \%$ respectively [71]. It is not uncommon for female athletes to resort to disordered eating patterns as they believe a low body weight will enhance their performance [72]. Increased rates of FAT in the athletic population are currently thought to be due to lack of athlete awareness and mental health disorders rather than the exercise itself [12]. Athlete awareness is currently poor, with a recent Australian study reporting that only $10 \%$ of female athletes had knowledge of FAT and that $22 \%$ of female athletes in 'lean-build' sports would take no action if amenorrhoeic [73-84]. There is currently no data on the relative risk of developing FAT in individuals who are not athletes as they increase their PA levels.

\section{Conclusions}

The benefits of physical activity are well documented and cover a multitude of significant public health issues. There are a number risks to increasing levels of PA which clinicians must be aware of when identifying inactive patients, implementing strategies to increase PA and when conducting research. If GPs are aware of these risks they can ensure that strategies are in place to reduce risks, spot early signs of any problems and can educate patients fully before they agree to start any intervention.

There are many interventions aimed at promoting the number of 'active' patients, however the evidence to support their use in this outcome is still inconclusive and requires further investigation. In view of the considerable benefits of increasing physical activity and the vast costs inactive patients place on the NHS, it is essential that clinicians stay current with these investigations and amend their clinical practice accordingly.

\section{Disclosure/Acknowledgement}

Ethical approval was not required for this article as no participants were required. The author has not received any funding from any organizations and has no conflicts of interests.

\section{References}

1. Lee IM, Shiroma EJ, Lobelo F, Puska P, Blair SN, et al. (2012) Effect of physical inactivity on major non-communicable diseases worldwide: an analysis of burden of disease and life expectancy. Lancet 380: 219-229.

2. Allender S, Foster C, Scarborough P, Rayner M (2007) The burden of physical activity-related ill health in the UK. J Epidemiol Community Health 61: 344-348.

3. Treasury HM (2010) Spending Review 2010. London, UK.

4. The NHS Information Centre and Lifestyles Statistics (2012) Statistics on obesity, physical activity and diet: England, 2012

5. Marcus BH, Williams DM (2006) Physical activity intervention studies: what we know and what we need to know: a scientific statement from the American Heart Association Council on Nutrition, Physical Activity, and Metabolism (Subcommittee on Physical Activity); Council on Cardiovascular Disease in the Young; and the Interdisciplinary Working Group on Quality of Care and Outcomes Research. Circulation 114: 2739-2752.

6. Wilcox S, Dowda M, Leviton LC, Bartlett-Prescott J, Bazzarre T, et al. (2008) Active for life: final results from the translation of two physical activity programs Am J Prev Med 35: 340-351.

7. Hébert ET, Caughy MO, Shuval K (2012) Primary care providers' perceptions of physical activity counselling in a clinical setting: a systematic review. $\mathrm{Br} \mathrm{J}$ Sports Med 46: 625-631.

8. Cho HJ, Sunwoo S, Song YM (2003) Attitudes and reported practices of Korean primary care physicians for health promotion. J Korean Med Sci 18: 783-790.

9. Douglas F, Torrance N, van Teijlingen E, Meloni S, Kerr A (2006) Primary care staff's views and experiences related to routinely advising patients about physical activity. A questionnaire survey. BMC Public Health 6: 138.

10. Graham RC, Dugdill L, Cable NT (2005) Health professionals' perspectives in exercise referral: implications for the referral process. Ergonomics 48: 14111422.

11. Le Masurier GC, Sidman CL, Corbin CB (2003) Accumulating 10,000 steps: does this meet current physical activity guidelines? Res Q Exerc Sport 74: 389394.

12. Booth FW, Roberts CK (2012) Lack of Exercise Is a Major Cause of Chronic Diseases. Compr Physiol 2(2): 1143-1211.

13. George CA, Leonard JP, Hutchinson MR (2011) The female athlete triad: a 
Citation: Cox P (2013) The Busy General Practitioner's Reference Guide to Increasing Physical Activity Levels in the British Population and Associated Benefits/Risks: A Review of the Literature. J Gen Pract 1: 101. doi: 10.4172/2329-9126.1000101

current concepts review: review. South African Journal of Sports Medicine 23: $50-56$

14. Physical Activity Guidelines Advisory Committee (2008) Physical Activity Guidelines Advisory Committee report, 2008. U.S. Department of Health and Human Services. Washington, DC, USA.

15. Leitzmann MF, Park Y, Blair A, Ballard-Barbash R, Mouw T, et al. (2007) Physical activity recommendations and decreased risk of mortality. Arch Intern Med 167: 2453-2460.

16. Warburton DE, Nicol CW, Bredin SS (2006) Health benefits of physical activity: the evidence. CMAJ 174: 801-809.

17. Stead LF, Bergson G, Lancaster T (2008) Physician advice for smoking cessation. Cochrane Database Syst Rev : CD000165.

18. Kang M, Marshall SJ, Barreira TV, Lee JO (2009) Effect of pedometer-based physical activity interventions: a meta-analysis. Res Q Exerc Sport 80: 648655

19. Elley CR, Kerse N, Arroll B, Robinson E (2003) Effectiveness of counselling patients on physical activity in general practice: cluster randomised controlled trial. BMJ 326: 793

20. Kennedy MF, Meeuwisse WH (2003) Exercise counselling by family physicians in Canada. Prev Med 37: 226-232.

21. Stott NC, Pill RM (1990) 'Advise yes, dictate no'. Patients' views on health promotion in the consultation. Fam Pract 7: 125-131.

22. Orrow G, Kinmonth AL, Sanderson S, Sutton S (2012) Effectiveness of physical activity promotion based in primary care: systematic review and meta-analysis of randomised controlled trials. BMJ 344: e1389.

23. Garrett S, Elley CR, Rose SB, O'Dea D, Lawton BA, et al. (2011) Are physical activity interventions in primary care and the community cost-effective? A systematic review of the evidence. Br J Gen Pract 61: e125-133.

24. Sørensen J, Sørensen JB, Skovgaard T, Bredahl T, Puggaard L (2011) Exercise on prescription: changes in physical activity and health-related quality of life in five Danish programmes. Eur J Public Health 21: 56-62.

25. Sørensen JB, Skovgaard T, Puggaard L (2006) Exercise on prescription in general practice: a systematic review. Scand J Prim Health Care 24: 69-74.

26. Murphy SM, Edwards RT, Williams N, Raisanen L, Moore G, et al. (2012) An evaluation of the effectiveness and cost effectiveness of the National Exercise Referral Scheme in Wales, UK: a randomised controlled trial of a public health policy initiative. J Epidemiol Community Health 66: 745-753.

27. Anokye NK, Trueman P (2011). "The cost-effectiveness of exercise referral schemes." BMC Public Health 11(954)

28. Pavey TG, Anokye N, Taylor AH, Trueman P, Moxham T, et al. (2011) The clinical effectiveness and cost-effectiveness of exercise referral schemes: a systematic review and economic evaluation. Health Technol Assess 15: i-xii, 1-254.

29. Isaacs AJ, Critchley JA, Tai SS, Buckingham K, Westley D, et al. (2007) Exercise Evaluation Randomised Trial (EXERT): a randomised trial comparing GP referral for leisure centre-based exercise, community-based walking and advice only. Health Technol Assess 11: 1-165, iii-iv.

30. National Institute of Health and Clinical Excellence (2006) A rapid review of the effectiveness of community-based walking and cycling programmes to promote physical activity in adults. NICE Public Health Collaborating Centre. London.

31. Varró A, Baczkó I (2010) Possible mechanisms of sudden cardiac death in top athletes: a basic cardiac electrophysiological point of view. Pflugers Arch 460: $31-40$

32. Bravata DM, Smith-Spangler C, Sundaram V, Gienger AL, Lin N, et al. (2007) Using pedometers to increase physical activity and improve health: a systematic review. JAMA 298: 2296-2304.

33. Hatano Y (1993) "Use of the pedometer for promoting daily walking exercise." International Council for Health, Physical Education, Recreation, 29: 4-8.

34. Jarrett J, Woodcock J, Griffiths UK, Chalabi Z, Edwards P, et al. (2012) Effect of increasing active travel in urban England and Wales on costs to the National Health Service. Lancet 379: 2198-2205.

35. Writing Group for the Activity Counseling Trial Research Group (2001) Effects of physical activity counseling in primary care: the Activity Counseling Trial: a randomized controlled trial. JAMA 286: 677-687.

36. Prochaska JO, Marcus BH (1994) The transtheoretical model: Applications to exercise. Advances in exercise adherence. Dishman RK. Champaign, IL, Human Kinetics.

37. Calfas KJ, Long BJ, Sallis JF, Wooten WJ, Pratt M, et al. (1996) A controlled trial of physician counseling to promote the adoption of physical activity. Prev Med 25: 225-233.

38. Marcus BH, Emmons KM, Simkin-Silverman LR, Linnan LA, Taylor ER, et al. (1998) Evaluation of motivationally tailored vs. standard self-help physical activity interventions at the workplace. Am J Health Promot 12: 246-253.

39. Naylor PJ, Simmonds G, Riddoch C, Velleman G, Turton P (1999) Comparison of stage-matched and unmatched interventions to promote exercise behaviour in the primary care setting. Health Educ Res 14: 653-666.

40. Blissmer B, McAuley E (2002) "Testing the requirements of stages of physical activity among adults: The comparative effectiveness of stage-matched, mismatched, standard care, and control interventions." Annals of Behavioural Medicine 24: 181-189.

41. Steptoe A, Rink E, Kerry S (2000) Psychosocial predictors of changes in physical activity in overweight sedentary adults following counseling in primary care. Prev Med 31: 183-194.

42. Myerburg RJ, Kessler KM, Bassett AL, Castellanos A (1989) A biological approach to sudden cardiac death: structure, function and cause. Am J Cardiol 63: $1512-1516$.

43. Corrado D, Michieli P, Basso C, Schiavon M, Thiene G (2007) How to screen athletes for cardiovascular diseases. Cardiol Clin 25: 391-397, v-vi.

44. Harmon KG, Asif IM, Klossner D, Drezner JA (2011) Incidence of sudden cardiac death in national collegiate athletic association athletes. Circulation 123: $1594-1600$

45. Maron BJ, Doerer JJ, Haas TS, Tierney DM, Mueller FO (2009) Sudden deaths in young competitive athletes: analysis of 1866 deaths in the United States, 1980-2006. Circulation 119: 1085-1092.

46. Papadakis M, Sharma S (2009) Electrocardiographic screening in athletes: the time is now for universal screening. Br J Sports Med 43: 663-668.

47. Kong MH, Fonarow GC, Peterson ED, Curtis AB, Hernandez AF, et al. (2011) Systematic review of the incidence of sudden cardiac death in the United States. J Am Coll Cardiol 57: 794-801.

48. Siscovick DS, Weiss NS, Fletcher RH, Lasky $T$ (1984) The incidence of primary cardiac arrest during vigorous exercise. N Engl J Med 311: 874-877.

49. Toscos T, Consolvo S, McDonald DW (2011) Barriers to physical activity: a study of self-revelation in an online community. J Med Syst 35: 1225-1242.

50. Maffulli N, Longo UG, Gougoulias N, Caine D, Denaro V (2011) Sport injuries: a review of outcomes. Br Med Bull 97: 47-80.

51. Toivanen AT, Heliövaara M, Impivaara O, Arokoski JP, Knekt P, et al. (2010) Obesity, physically demanding work and traumatic knee injury are major risk factors for knee osteoarthritis--a population-based study with a follow-up of 22 years. Rheumatology (Oxford) 49: 308-314.

52. Bauer R, Steiner S (2009) Injuries in the European Union: Statistics Summary 2005-2007. EuroSafe \& Kuratorium für Verkehrssicherheit. Vienna, Austria, European Commission, Health and Consumers Directorate-General.

53. Klügl M, Shrier I, McBain K, Shultz R, Meeuwisse WH, et al. (2010) The prevention of sport injury: an analysis of 12,000 published manuscripts. Clin $J$ Sport Med 20: 407-412.

54. Matheson GO, Mohtadi NG, Safran M, Meeuwisse WH (2010) Sport injury prevention: time for an intervention? Clin J Sport Med 20: 399-401.

55. Shaw L, Finch CF (2008) Injuries to junior club cricketers: the effect of helmet regulations. Br J Sports Med 42: 437-440.

56. Macan J, Bundalo-Vrbanac D, Romić G (2006) Effects of the new karate rules on the incidence and distribution of injuries. Br J Sports Med 40: 326-330.

57. Verhagen EA, van Stralen MM, van Mechelen W (2010) Behaviour, the key factor for sports injury prevention. Sports Med 40: 899-906.

58. Mitchell R, Finch C, Boufous S (2010) Counting organised sport injury cases: 
Citation: Cox P (2013) The Busy General Practitioner's Reference Guide to Increasing Physical Activity Levels in the British Population and Associated Benefits/Risks: A Review of the Literature. J Gen Pract 1: 101. doi: 10.4172/2329-9126.1000101

evidence of incomplete capture from routine hospital collections. J Sci Med Sport 13: 304-308.

59. Moran DS, Evans R, Arbel Y, Luria O, Hadid A, et al. (2011) Physical and psychological stressors linked with stress fractures in recruit training. Scand J Med Sci Sports.

60. Finch CF (2012) Getting sports injury prevention on to public health agendas - addressing the shortfalls in current information sources. Br J Sports Med 46: $70-74$

61. Hou WH, Tsauo JY, Lin CH, Liang HW, Du CL (2008) Worker's compensation and return-to-work following orthopaedic injury to extremities. J Rehabil Med 40: $440-445$.

62. MacKenzie EJ, Morris JA Jr, Jurkovich GJ, Yasui Y, Cushing BM, et al. (1998) Return to work following injury: the role of economic, social, and job-related factors. Am J Public Health 88: 1630-1637.

63. Rusch MD, Dzwierzynski WW, Sanger JR, Pruit NT, Siewert AD (2003) Return to work outcomes after work-related hand trauma: the role of causal attributions. J Hand Surg Am 28: 673-677.

64. Iles RA, Davidson M, Taylor NF (2008) Psychosocial predictors of failure to return to work in non-chronic non-specific low back pain: a systematic review. Occup Environ Med 65: 507-517.

65. Kendrick D, O'Brien C, Christie N, Coupland C, Quinn C, et al. (2011) The impact of injuries study. multicentre study assessing physical, psychological, social and occupational functioning post injury--a protocol. BMC Public Health 11: 963

66. Bauman J (2005) Returning to play: the mind does matter. Clin J Sport Med 15: $432-435$

67. Birch K (2005) "ABC of sports and exercise medicine: Female athlete triad". BMJ 330: 240 .

68. Nattiv A, Loucks AB, Manore MM, Sanborn CF, Sundgot-Borgen J, et al. (2007) American College of Sports Medicine position stand. The female athlete triad. Med Sci Sports Exerc 39: 1867-1882.

69. Reinking MF, Alexander LE (2005) Prevalence of Disordered-Eating Behaviors in Undergraduate Female Collegiate Athletes and Nonathletes. J Athl Train 40: 47-51.

70. Kyriazis SM, Kukuljan S (2012) "Energy deficiency, menstrual disturbances and low bone mass: What do Australian exercising females know about the female athlete triad." Int J Sport Nutr Exerc Metab: [Epub ahead of print].
71. Clay FJ, Newstead SV, Watson WL, McClure RJ (2010) Determinants of return to work following non life threatening acute orthopaedic trauma: a prospective cohort study. J Rehabil Med 42: 162-169.

72. Corrado D, Migliore F, Basso C, Thiene G (2006) Exercise and the risk of sudden cardiac death. Herz 31: 553-558.

73. George ES, Kolt GS, Duncan MJ, Caperchione CM, Mummery WK, et al (2012) A review of the effectiveness of physical activity interventions for adult males. Sports Med 42: 281-300.

74. Information Services Division (2011) "General practice - Practice Team Information (PTI) Statistics and Analysis. (Accessed 1/7/2012)."

75. Jonas S, Phillips EM (2009) ACSM's Exercise is Medicine: A Clinician's Guide to Exercise Prescription (1stedn). Springhouse Publishing Company, USA.

76. Kaner EF, Beyer F, Dickinson HO, Pienaar E, Campbell F, et al. (2007) Effectiveness of brief alcohol interventions in primary care populations. Cochrane Database Syst Rev : CD004148.

77. Kvist J, Ek A, Sporrstedt K, Good L (2005) Fear of re-injury: a hindrance for returning to sports after anterior cruciate ligament reconstruction. Knee Surg Sports Traumatol Arthrosc 13: 393-397.

78. Manley AF (1996) Physical activity and health: a report of the Surgeon General US Department of Health and Human Services. Atlanta, Centers for Disease Control and Prevention, National Center for Chronic Disease Prevention and Health Promotion, USA.

79. National Institute of Health and Clinical Excellence (2006) Four commonly used methods to increase physical activity (Public Health Intervention Guidance no. 2), London, UK.

80. National Institute of Health and Clinical Excellence (2008) Guide to Methods of Technology Appraisals. National Institute of Health and Clinical Excellence.

81. National Physical Activity Plan (2010) National Physical Activity Plan For The United States. Columbia, USA.

82. Pavey TG, Taylor AH, Fox KR, Hillsdon M, Anokye N, et al. (2011) Effect of exercise referral schemes in primary care on physical activity and improving health outcomes: systematic review and meta-analysis. BMJ 343: d6462.

83. Tudor-Locke C, Lutes $L$ (2009) Why do pedometers work?: a reflection upon the factors related to successfully increasing physical activity. Sports Med 39 981-993.

84. World Health Organisation (2010) Global recommendations on physical activity for health. Geneva, Switzerland. 